\title{
Estudo do Problema de Corte e Planejamento da Produção Aplicado à Industria Moveleira de Pequeno Porte
}

\author{
Beatriz de Souza Bonfim ${ }^{1}$ \\ Hadassa Maria da Silva ${ }^{2}$ \\ Daniele Costa Silva ${ }^{3}$ \\ Departamento de Matemática, UTFPR, Cornélio Procópio, PR
}

Resumo. Neste trabalho é feito o estudo dos problemas de corte e planejamento aplicados à uma indústria moveleira de pequeno porte. Ambos os problemas são modelados por meio de programação linear inteira e solucionados separadamente e também de forma combinada. Concluiu-se que ambas as abordagens de resolução podem ser utilizadas de forma comparativa na tomada de decisões.

Palavras-chave. Planejamento da Produção, Corte de Estoque, Programação Linear

\section{Estudo de caso: M\&M Móveis}

Em uma indústria moveleira de pequeno porte o processo produtivo consiste no corte da matéria-prima, de modo a gerar as peças necessárias para a confecção dos móveis. Porém, antes de inicializar este processo, decisões referentes ao planejamento da produção e ao corte, devem ser tomadas. Usualmente, após estimada a demanda é determinado o quanto de cada produto será produzido e estocado em cada período para, posteriormente, determinar como será feito o corte da matéria-prima. O que muitas vezes é feito de forma improvisada implicando em resultados não satisfatórios. Neste ponto, a programação matemática e o uso de recursos computacionais podem ser bastante benéficos.

Com o intuito de investigar os problemas de corte e planejamento neste contexto, foi feito um estudo de caso com a M\&M Móveis, indústria criada pelas autoras do trabalho com base em dados fornecidos por pequenas empresas moveleiras da cidade de Cornélio Procópio-PR, cuja principal atividade é a produção de mesas e cadeiras. Foram consideradas a abordagem usual e também a combinada, dada a crescente de trabalhos que propõe essa abordagem como meio de redução de custos [1].

Para tanto, são propostos modelos de programação linear inteira ((1) e (2)), os quais e sua junção são solucionados através do método Branch and Bound [2] com auxílio do Solver. ${ }^{4}$

\footnotetext{
${ }^{1}$ beatriz.bonfim306@outlook.com

${ }^{2}$ hadassa.silva.n@hotmail.com

${ }^{3}$ danielesilva@utfpr.edu.br

${ }^{4}$ Ferramenta de otimização presente no Excel
} 
Planejamento da Produção (1)

Min. $\sum_{i=1}^{n} \sum_{t=1}^{m} c p_{i t} x d_{i t}+\sum_{i=1}^{n} \sum_{t=1}^{m} c e_{i t} x e_{i t}$

s.a. $x d_{i t}+x e_{i t-1}=d_{i t}$

$\sum_{i=1}^{n} h_{i} x d_{i t}+\sum_{i=1}^{n} h_{i} x e_{i t} \leq h p_{t}$

$x e_{i t} \leq e_{i t}$

$x d_{i t}, x e_{i t} \geq 0$, inteiro.
Estratégia de Corte (2)

Min. $\sum_{j=1}^{p} \sum_{t=1}^{m} c_{l} y_{j t}+\sum_{k=1}^{q} \sum_{t=1}^{m} c e_{k t} p e_{k t}$

s.a $\sum_{j=1}^{p} \sum_{t=1}^{m} q_{k j} y_{j t}+e_{k t-1} \geq d_{k t}$

$h_{j} y_{j t} \leq h c_{t}$

$p e_{k t} \leq e_{k t}$

$y_{j t} \geq 0$, inteiro.

Onde: $x d_{i t}$ - quantidade do produto $i$ para atender a demanda do período $t, x e_{i t}$ quantidade do produto $i$ estocada para o período $t+1, y_{j t}$ - número de vezes que o padrão de corte $j$ é utilizado no período $t, c p_{i t}$ - custo da produção do produto $i$ no período $t$, $c e_{i t} / c e_{k t}$ - custo de estocagem do produto $i$ ou peça $k$ no período $t, c_{l}$ - custo da matéria prima $l, d_{i t} / d_{k t}$ - demanda de produto $i$ ou peça $k$ no período $t, q_{k j}$ - quantidade de peças $k$ no padrão $j, p e_{k t}=d_{k t}-q_{k j} y_{j t}$ - quantidade de peça $k$ estocada no período $t, h_{i} / h_{j}$ - tempo gasto para a produção do produto $i$ ou corte do padrão $j, h p t / h c t$ - tempo disponível para produção ou corte no período $t$ e $e_{i t} / e_{k t}$ - capacidade de estoque do produto $i$ ou peça $k$ no período $t$.

Através de testes computacionais em diferentes cenários, verificou-se que há casos em que solucionar os problemas de forma combinada é melhor do que solucioná-los separadamente e outros em que o inverso ocorre. Por exemplo, considerando 2 períodos com custo de produção de $R \$ 15,00$ para a mesa e $R \$ 10,00$ para a cadeira, custo de estocagem de $R \$$ 4,00 mesa, $\mathrm{R} \$ 2,00$ cadeira e variando de $\mathrm{R} \$ 0,13$ a $\mathrm{R} \$ 0,40$ para as peças, custo de matéria prima variando de $\mathrm{R} \$ 5,77$ a $\mathrm{R} \$ 135,07$, capacidade de produção de 176 horas no período 1 e 184 horas no período 2 e demanda de 20 mesas e 19 cadeiras no período 1 e de 110 mesas e 10 cadeiras no período 2; é mais rentável analisar os problemas conjuntamente, uma vez que a demanda é atendida a um custo total de $\mathrm{R} \$ 5999,98$ e com desperdício de 423 peças. Já separadamente, o custo total é de $\mathrm{R} \$ 6020,65$ e o desperdício de 537 peças. Entretanto, nestas mesmas condições mas com demanda de 21 mesas e 28 cadeiras no período 1 e de 41 mesas e 44 cadeiras no período 2, analisar separadamente é mais conveniente, já que o custo total é de $\mathrm{R} \$ 4054,81$ com desperdício de 199 peças e conjuntamente o custo é de $\mathrm{R} \$ 4063,84$ e o desperdício de 222 peças. Assim, conclui-se que ambas abordagens podem ser utilizadas de forma comparativa na tomada de decisões.

\section{Referências}

[1] S. G. Santos, S. A. Araújo and S. Rangel, Integrated cutting machine programming and lot sizing infurniture industry, PODes, vol. 3, 1-17, (2011).

[2] R. J. Vanderbei, Linear Programming - Foundations and Extensions, Integer Programming, Cap. 23, vol. 196, (2014). 